\title{
APRESENTAÇÃO DO DOSSIÊ: FONOLOGIA E VARIAÇÃO FONÉTICO-FONOLÓGICA
}

Este número da Letrônica compõe-se de quatorze artigos distribuídos entre fonética, fonologia e variação, agrupados em cinco áreas temáticas.

O leitor interessado em variação encontra análises pautadas no paradigma laboviano e na dialetologia pluridimensional; as primeiras contam com ferramentas estatísticas, a fim de verificar como contextos linguísticos e sociais podem influenciar na escolha de produção do falante; as segundas estão inseridas na sociolinguística variacionista com trabalhos que abordam diferentes aspectos: saliência fônica e concordância verbal, acento secundário e epêntese, monotongação de ditongos decrescentes com variação na escrita. Quanto à Dialetologia, considerada em seu espaço geográfico, a atenção volta-se para as dimensões diastrática e a diageracional - isto é, pluridimensional. Há uma visão contínua da variação linguística como reflexo de contatos entre línguas ou entre variedades linguísticas distintas.

Há trabalhos neste dossiê que dizem respeito à Fonologia Gestual, modelo teórico que, diferentemente das demais teorias fonológicas, insere a variável tempo em seu primitivo de análise: o gesto articulatório. 0 gesto é definido como caracterizações de eventos fisicamente reais e discretos que se desenrolam durante a produção de fala, e é especificado por um conjunto de variáveis do trato vocal relacionadas, a exemplo de protrusão e abertura labial. 0 gesto é concebido como algo mais dinâmico e complexo do que o movimento de determinado articulador por si só.

Outro modelo de análise contemplado nesta edição é a Teoria da Otimidade, proposta de base gerativa que concebe a gramática como resultado da interação entre restrições universais violáveis. Nesse modelo, cada possível output linguístico (forma de superfície) correspondente a determinado input (forma subjacente) é avaliado por uma hierarquia de restrições, de modo que a forma escolhida como ótima - isto é, o output 
que efetivamente ocorre na língua - é o que viola em menor número as restrições que constituem dada gramática.

Há um artigo que discute a debucalização, em que há perda de articulação na cavidade bucal, sob o prisma de diferentes teorias, quais sejam: Estruturalismo, Gerativismo, Fonologia Autossegmental e Geometria de Traços.

O Léxico foi tema de dois estudos. Nos moldes da Teoria de Exemplares, cada falante possui, na memória, representações lexicais (os exemplares) que vão sendo estocadas com base no uso, isto é, nas palavras que já foram ouvidas por ele. Por outro lado, nos moldes da Difusão Lexical, mudanças sonoras são foneticamente abruptas e lexicalmente graduais, ou seja, o condicionamento lexical atua, num primeiro momento, mais fortemente do que o condicionamento fonético: os sons se modificam numa palavra isolada e vão-se propagando no léxico gradualmente para outras palavras com contexto fonético semelhante.

Para o leitor com interesse em modelos de aquisição fonológica, há um estudo que analisa dados a partir do Modelo Implicacional de Complexidade de Traços (MICT). O MICT fundamenta-se no modelo de Geometria de Traços e na teoria de inventários fonológicos com base em restrições, e entende que existem leis implicacionais entre os traços, de tal maneira que a existência de segmentos com traços marcados no inventário fonológico infantil implica na presença traços não marcados. Nessa visão, a criança inicia o processo de aquisição com um inventário mínimo de segmentos, que fazem parte da Gramática Universal - compostos por traços não marcados, e, à medida que vai estabelecendo seu inventário fonológico, acrescenta traços marcados.

Com relação à Fonética, três línguas indígenas foram estudadas sob o prisma da dispersão acústica de vogais. O objetivo é investigar inventários vocálicos que, teoricamente, tendem a maximizar o espaço acústico, pois os sons estão propensos, primeiramente, a ser maximamente diferentes entre si - só depois os espaços intermediários são utilizados.

Também tem seu lugar nesta edição duas teorias de Processamento Fonológico, em que operações cognitivas são consideradas a fim de verificar a produção e a compreensão linguísticas em desvio fonológico, bem como compará-las ao desenvolvimento normal. 
Com relação à distribuição dos artigos que constituem este volume, apresentamse primeiramente sete trabalhos que representam a área temática de variação fonéticofonológica. No artigo (1), Ana Paula Correa da Silva Biasibetti discute, com base na Teoria de Exemplares, os resultados de uma análise sociolinguística sobre a elevação sem motivação aparente das vogais médias pretônicas em dados de fala da capital gaúcha pertencentes ao Banco VARSUL (Variação Linguística Urbana do Sul do País). A pesquisa contribui para a compreensão do status mais recente dessa regra variável na fala porto-alegrense, bem como para o aprimoramento do método de análise, pois o Rbrul tornou possível uma análise simultânea das variáveis contextuais e lexicais e, consequentemente, o trabalho trouxe uma confirmação estatística aos resultados de trabalhos anteriores (não havia comprovações estatísticas até então devido à falta de ferramentas). 0 artigo (2) de Raquel Gomes Chaves trata da variável saliência fônica em diferentes pesquisas sociolinguísticas sobre concordância verbal de terceira pessoa do plural (eles falam eles falaØ) e redução e/ou desnasalização de ditongos nasais átonos

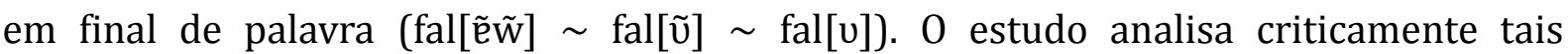
pesquisas, bem como os critérios para a constituição da escala de saliência fônica. Em (3), Tatiana Keller e Evellyne Patrícia Figueiredo de Sousa Costa buscam verificar a relação entre acento secundário e epêntese vocálica em dados do português portoalegrense do Banco VARSUL. 0 principal objetivo das autoras é verificar a possibilidade de maior aplicação de epêntese em palavras com número ímpar em sílabas pretônicas do que em palavras com número par de sílabas nessa pauta. 0 artigo (4) de Sabrina Gewehr-Borella discute a produção variável de oclusivas por falantes bilíngues hunsriqueano-português em contexto de leitura em língua portuguesa, a partir de dados do Projeto Alma-H (Atlas Linguístico-Contatual das Minorias Alemãs na Bacia do Prata: Hunsrückisch). 0 estudo fundamenta-se na dialetologia pluridimensional e conta com dados de seis pontos de pesquisa no Rio Grande do Sul, de modo que, a partir dos aspectos sob investigação, observa-se variação diatópica, diageracional e diastrática no uso das oclusivas. $\mathrm{O}$ artigo (5) de Camila de Bona faz uma revisão de estudos referentes ao papel da frequência lexical na variação fonológica condicionada morfologicamente e analisa o tratamento da frequência lexical em diferentes modelos teóricos, retomando estudos realizados no Brasil que consideraram o papel dessa variável. Os dois artigos que seguem discutem particularidades de dois processos fonológicos: a harmonização e 
a debucalização. No artigo (6), Graziela Pigatto Bohn discute o bloqueio no caso de harmonia vocálica de altura e a opcionalidade no caso de harmonia vocálica de ATR no português brasileiro, via Teoria da Otimidade. Os resultados da análise indicam que ambos os tipos de harmonia vocálica podem ser explicados pelo mesmo conjunto de restrições, cuja principal diferença reside na adjacência, interpretada por uma reordenação de restrições. Em (7), José Júnior Dias da Silva e Consuelo de Paiva Godinho Costa discutem o fenômeno da debucalização e sua representação na fonologia autossegmental. Especificamente, trata de uma análise de fricativas alveolares e pós alveolares, que passam a ser laringais [h] em contexto medial e final de palavra. 0 estudo conta com dados do português falado em Vitória da Conquista-BA. São apontados entraves teóricos em diferentes modelos (Estruturalismo, Gerativismo, Fonologia Autossegmental e Geometria de Traços) para a adequada representação desse fenômeno fonológico.

Os próximos dois artigos estão relacionados à aquisição fonológica atípica do português brasileiro. 0 trabalho (8), de Michele Gindri Vieira, investiga o desempenho de crianças com desvio fonológico em tarefas que envolvam memória de trabalho (por meio de repetição de sequências de dígitos e de repetição de não palavras) e consciência fonológica (tarefas de consciência silábica e de fonêmica). 0 estudo conta com uma amostra composta por 28 crianças não alfabetizadas, com idade entre quatro anos e seis anos e sete meses. Uma das questões centrais foi verificar se essas habilidades estão relacionadas entre si. No artigo (9), Vanessa Henrich e Letícia Pacheco Ribas apresentam e discutem o perfil de aquisição das consoantes róticas em dados de fala de crianças do Banco de Dados VALDEF (Variação Linguística e Aquisição com Desvio Fonológico: Questões para Inclusão Social). O estudo analisa os róticos em onset simples nos dados de 111 crianças de ambos os sexos, com idade entre 4 e 10 anos e com diferentes graus de desvio fonológico.

Contempla a relação entre variação fonético-fonológica e escrita o artigo (10), no qual Taíse Simioni e Éder Lupe Rodrigues discutem resultados de um estudo sobre monotongação de ditongos orais decrescentes em dados de escrita de crianças em séries iniciais do Ensino Fundamental do município gaúcho de Bagé. 0 estudo mostra que a monotongação na escrita apresenta variação relacionada a fatores como ditongo, sexo e escolaridade. Quanto aos fatores linguísticos, o tepe favorece a aplicação de 
monotongação.

Representa a área de línguas indígenas o artigo (11) de Fabíola Baraúna, Alessandra Brito e Gessiane Picanço, que apresentam e analisam a dispersão acústica das vogais em três línguas tupi. Essas línguas foram consideradas porque o Asuriní e o Wayampí têm vogais com status indefinido, o que foi contemplado na pesquisa; quanto ao Mundurukú, uma língua excepcional, pois não possuía o triângulo /i, u, a/ em seu sistema vocálico. Interessantemente, os resultados da análise acústica mostram que, nos dias de hoje, o Mundurukú parece ter uma compensação nas vogais, aproximando essa língua da simetria. De modo geral, o estudo contribui para uma descrição mais precisa das categorias fonéticas vocálicas de cada língua em análise.

0 último bloco tem por tema aquisição de inglês como língua estrangeira. 0 artigo (12) de Athany Gutierres apresenta uma análise variacionista da aquisição fonológica da nasal velar [y] por aprendizes brasileiros de inglês como L2. Mostra que a variação na fala dos aprendizes é um sistema intermediário, isto é, a interlíngua é um sistema natural, com características tanto da L1 quanto da L2; está propenso a mudanças em diferentes etapas de seu desenvolvimento que nivela regularidade na variação. Segundo a autora, a variante alternativa (palatal) prevalece em relação à variável dependente (velar). Em (13), Bruna Koch Schmitt e Ubiratã Kickhöfel Alves tratam da aquisição de /p/ e /t/ em coda medial por aprendizes brasileiros - em sequências /pt/ e /kt/. São analisadas produções em português e em inglês de 7 informantes, com a finalidade de comparar, nas duas línguas, os padrões acústicos encontrados nas tentativas de produção das codas. Os autores firmam-se em pressupostos da Teoria da Otimalidade Estocástica e da Fonologia Gestual para explicar padrões acústicos que eram desconsiderados pelas análises fonológicas tradicionais. Encerra este número o trabalho (14) de Fernando Cabral Alves e Rubens Marques de Lucena sobre aquisição da lateral silábica do inglês. 0 estudo investiga dados de fala em língua inglesa de 12 informantes e analisa-os a partir da Teoria da Otimidade Estocástica. 0 trabalho contribui para a descrição e explicação de possíveis outputs do input /əl/ e aponta para a importância do papel do input na aquisição de uma segunda língua. 
Contribuíram para este dossiê estudantes e pesquisadores de diferentes universidades do Brasil: Universidade Federal do Pará, Universidade Federal da Paraíba, Universidade Estadual do Sudoeste da Bahia, Instituto Federal de Ciência e Tecnologia da Bahia, Universidade de São Paulo, Universidade Federal de Santa Catarina, Universidade Federal do Pampa, Universidade Federal de Santa Maria, Universidade Federal de Ciências da Saúde de Porto Alegre, Universidade Federal do Rio Grande do Sul e Pontifícia Universidade Católica do Rio Grande do Sul.

Por fim, vale observar que os artigos publicados neste número da Letrônica são o resultado de estudos que vêm sendo realizados na área de fonologia e na área da interface fonética-fonologia.

As organizadoras,

Leda Bisol e Eneida de Goes Leal (Professoras responsáveis - PUCRS)

Ivanete Mileski (Doutoranda - PUCRS) 